\title{
Amygdala NRGI-ErbB4 Is Critical for the Modulation of Anxiety-Like Behaviors
}

\author{
Lin-Lin Bi ${ }^{1,2,3,5}$, Xiang-Dong Sun ${ }^{1,2,4,5}$, Jie Zhang ${ }^{1,2}$, Yi-Sheng Lu ${ }^{4}$, Yi-Hua Chen ${ }^{1,2}$, Jue Wang ${ }^{1,2}$, Fei Geng ${ }^{1,2}$, \\ Fang Liu', Meng Zhang ${ }^{1,2}$, Ji-Hong Liu ${ }^{1,2}$, Xiao-Wen Li ${ }^{1,2}$, Lin Mei*, 1,2,4 and Tian-Ming Gao*, ${ }^{*, 2}$ \\ 'State Key Laboratory of Organ Failure Research, Department of Neurobiology, School of Basic Medical Sciences, Southern Medical University, \\ Guangzhou, China; ${ }^{2}$ Key Laboratory of Psychiatric Disorders of Guangdong Province, Southern Medical University, Guangzhou, China; ${ }^{3}$ Institute for \\ Brain Research, Huazhong University of Science and Technology, Wuhan, China; ${ }^{4}$ Department of Neuroscience and Regenerative Medicine, \\ Medical College of Georgia, Georgia Regents University, Augusta, GA, USA
}

\begin{abstract}
Anxiety disorder is related to the pathophysiology of psychiatric diseases, including major depression, substance abuse, and schizophrenia. The amygdala is important for manifestation and modulation of anxiety. However, relatively little is known regarding the mechanisms that control the amygdala inhibitory activity that is involved in anxiety. We found that almost all ErbB4, which is the only autonomous receptor of neuregulin I (NRGI) in the basolateral amygdala (BLA), was expressed in GABAergic neurons. Endogenous NRG I-ErbB4 signaling pathway in the BLA could modulate anxiety-like behaviors and GABA release, whereas it had no effect on glutamatergic transmission. The administration of NRGI into the BLA of high-anxiety mice alleviated their anxiety and enhanced GABAergic neurotransmission. Moreover, exogenous NRGI also produced an anxiolytic effect in the stressed mice. Together, these observations indicated that NRGI-ErbB4 signaling is critical to maintaining GABAergic activity in the amygdala and thus to modulating anxiety-like behaviors. Because NRGI and ErbB4 are susceptibility genes of schizophrenia, our findings might also help to explain the potential mechanism of emotional abnormality in schizophrenia.

Neuropsychopharmacology (20I5) 40, 974-986; doi:I0.1038/npp.20 I4.274; published online 19 November 20I4
\end{abstract}

\section{INTRODUCTION}

Anxiety disorder is one of the most common psychiatric diseases (28\% lifetime prevalence; Kessler et al, 2005) and contributes to the etiology of major depression, substance abuse, and schizophrenia (Buckley et al, 2009; Koob, 2009; Ressler and Mayberg, 2007). Despite its high prevalence, the underlying molecular mechanisms of anxiety remain unclear. Classical 1,4-benzodiazepines as standard treatment for anxiety disorders are not consistently effective (Johnson and Rodgers, 1996). Better therapeutic strategies require a deeper understanding of anxiety pathophysiological mechanisms.

The amygdala is critical for processing fearful emotions and anxiety (Hajizadeh Moghaddam et al, 2008; LeDoux, 2000; Muller et al, 1997; Scheel-Kruger and Petersen, 1982; Zarrindast et al, 2008). Its basolateral nuclei (basolateral

* Correspondence: Professor T-M Gao, State Key Laboratory of Organ Failure Research, Department of Neurobiology, School of Basic Medical Sciences, Guangzhou 510515, China, Tel: +86 2061648617, Fax: +8620 6I648I6I, E-mail: tgao@smu.edu.cn or Professor L Mei, Department of Neuroscience and Regenerative Medicine, Medical College of Georgia, Georgia Regents University, Augusta, GA 30912, USA, Tel: +0I 70672 I 8775, Fax: +0I 7064346432 ,

E-mail: Imei@gru.edu

${ }^{5}$ These authors contributed equally to this work.

Received 3 July 20 I; revised 8 September 20।4; accepted 5 October 2014; accepted article preview online 13 October 2014 amygdala (BLA)) receive sensory inputs from the cortex and thalamus and relay to the central nuclei (CEA), where projection neurons innervate neurons in the brainstem and the hypothalamus (Johansen et al, 2011; Krettek and Price, 1978; McDonald, 1998; Turner and Herkenham, 1991; Tye et al, 2011). Patients with anxiety disorder might have abnormal neuronal activity from the BLA (Etkin et al, 2009; Tye et al, 2011), in particular, GABAergic activity of the BLA (Hajizadeh Moghaddam et al, 2008; Muller et al, 1997; Scheel-Kruger and Petersen, 1982). However, the regulatory mechanisms of GABAergic activity in the amygdala for anxiety have not been studied extensively.

Neuregulin-1 (NRG1) is a trophic factor that belongs to a family of growth factors (Mei and Xiong, 2008). NRG1 contains an epidermal growth factor (EGF)-like domain that can act through ErbB receptor tyrosine kinases (Mei and Xiong, 2008). Among ErbB receptors, ErbB4 is the only autonomous tyrosine kinase that can be activated by NRG1. In contrast, ErbB2 must act by forming heterodimers with other ligand-bound ErbBs, whereas the kinase function of ErbB3 is impaired, although it can bind to NRG1. NRG1 and ErbB4 are expressed in developing nervous systems and in adult brains (Garcia et al, 2000; Huang et al, 2000). Notably, ErbB4 is expressed specifically in interneurons (Lai and Lemke, 1991; Shamir et al, 2012; Woo et al, 2007) and NRG1 promotes GABA release in cortical and hippocampal slices through ErbB4 (Chen et al, 2010a, b; Wen et al, 2010; Woo 
et al, 2007). Although NRG1 and ErbB4 are present in the amygdala (Lai and Lemke, 1991; Shamir et al, 2012; Woo et al, 2007), their roles in regulating anxiety remains unclear.

Here, we investigated whether amygdala NRG1-ErbB4 signaling modulates anxiety-like behaviors. Furthermore, we determined whether NRG1-ErbB4 regulates the GABAergic and/or glutamatergic transmission in the amygdala. We found that blocking NRG1-ErbB4 signaling in the BLA enhanced anxiety-like behaviors and, concomitantly, inhibited GABA release. The high-anxiety mice expressed a low level of both NRG1 and ErbB4, specifically in the amygdala, and the administration of exogenous NRG1 reversed their anxiety behaviors and enhanced GABAergic neurotransmission. In addition, an anxiolytic effect of NRG1 was also observed in the stressed mice. Our findings suggest that the NRG1-ErbB4 signaling pathway is critical for anxiety control, identifying a novel pathophysiological mechanism.

\section{MATERIALS AND METHODS}

\section{Mice}

Adult male C57 mice and transgenic mice (10-12 weeks, average weight, 20-25 g) were housed in standard laboratory cages ( 4 to 5 per cage) and on a $12 \mathrm{~h}$ light/dark cycle (lights on at $0800 \mathrm{~h}$ ) with a constant room temperature of 21-25 ${ }^{\circ} \mathrm{C}$. Food and water were available ad libitum. Behavioral testing was performed during the light cycle between $1000 \mathrm{~h}$ and $1700 \mathrm{~h}$. Procedures were conducted in accordance with the Chinese Council on Animal Care Guidelines. Efforts were made to minimize animal suffering and to reduce the number of animals used.

Heart-rescued ErbB4 knockout mice have been described previously (Tidcombe et al, 2003). GAD-GFP mice have been used to provide morphological and electrophysiological evidence of GABAergic interneurons for which the synapse project onto glutamatergic pyramidal neurons (Chieng et al, 2011; Marowsky et al, 2005; Silberman et al, 2008; Tamamaki et al, 2003). For more details on the generation and expression properties of ErbB4-Cre-ERT2 mice, please go to http:// transgenicmouse.alleninstitute.org. Adult ErbB4-2A-CreERT2 Ai14 mice were injected intraperitoneally for 5 consecutive days with $1 \mathrm{mg}$ of tamoxifen (Sigma).

\section{Reagents}

NRG1 contains the entire EGF domain of $\beta$-type NRG1 (rHRG $\beta 177-244$; Holmes et al, 1992). As previously reported, Ecto-ErbB4 was extracted from stable HEK23 cells (Woo et al, 2007). BMI was purchased from Tocris Bioscience. AG1478 was purchased from Calbiochem. PD158780 was purchased from Calbiochem. Other chemicals were purchased from Sigma-Aldrich. The reagents were dissolved in artificial cerebrospinal fluid (ACSF), which was freshly prepared before application. The concentration of DMSO (Sigma) that was used for the solution was $<0.1 \%$.

\section{Slice Preparation}

Mice were anesthetized with ketamine/xylazine and decapitated, and the brains were quickly removed to ice-cold oxygenated modified ACSF that contained (in mM): 250 glycerol, $2 \mathrm{KCl}, 10 \mathrm{MgSO}_{4}, 0.2 \mathrm{CaCl}_{2}, 1.3 \mathrm{NaH}_{2} \mathrm{PO}_{4}, 26$ $\mathrm{NaHCO}_{3}$, and 10 glucose. Coronal slices $(300 \mu \mathrm{m})$ that contained amygdala were prepared using a VT-1000S vibratome (Leica, Germany) and were subsequently transferred to a storage chamber that contained normal ACSF (in $\mathrm{mM})\left(126 \mathrm{NaCl}, 3 \mathrm{KCl}, 1 \mathrm{MgSO}_{4}, 2 \mathrm{CaCl}_{2}, 1.25 \mathrm{NaH}_{2} \mathrm{PO}_{4}, 26\right.$ $\mathrm{NaHCO}_{3}$, and 10 glucose) for $30 \mathrm{~min}$ at $32{ }^{\circ} \mathrm{C}$ and then were held at room temperature $\left(25 \pm 1{ }^{\circ} \mathrm{C}\right)$ for an additional $1-6 \mathrm{~h}$ before the experimental recordings. All of the solutions were saturated with $95 \% \mathrm{O}_{2} / 5 \% \mathrm{CO}_{2}$ ( $\mathrm{vol} / \mathrm{vol}$ ).

\section{Electrophysiological Recordings}

The slices were placed in the recording chamber that was superfused $(2 \mathrm{ml} / \mathrm{min})$ with ACSF at $32-34{ }^{\circ} \mathrm{C}$. Whole-cell patch-clamp recording of lateral amygdala neurons were obtained under IR-DIC visualization (Zeiss, Axioskop 2). We chose pyramidal neurons as experimental targets that were identified by the typical phenotype of large, pyramidal-like somata and firing adaption. AMPA receptormediated excitatory postsynaptic currents (AMPAReEPSCs) were evoked at $-70 \mathrm{mV}$ by electrical stimulation of thalamic input pathway with a two-concentric bipolar stimulating electrode (FHC) at a frequency of $0.05 \mathrm{~Hz}$ in the presence of the $\mathrm{GABA}_{\mathrm{A}}$ receptor antagonist BMI $(20 \mu \mathrm{M})$ and AP5 $(100 \mu \mathrm{M})$. NMDAR-EPSCs were evoked at $+30 \mathrm{mV}$ in the presence of CNQX $(20 \mu \mathrm{M})$ and BMI $(20 \mu \mathrm{M})$. The pipette solution (input resistance: 2-5 M $\Omega$ ) contained: $105 \mathrm{mM}$ K-gluconate, $30 \mathrm{mM} \mathrm{KCl}, 10 \mathrm{mM}$ Hepes, $10 \mathrm{mM}$ phosphocreatine, $4 \mathrm{mM}$ ATP-Mg, $0.3 \mathrm{mM}$ EGTA, and $5 \mathrm{mM}$ QX314 (pH 7.35, $285 \mathrm{mOsm})$. To record the mEPSCs, pyramidal neurons were held at $-70 \mathrm{mV}$ with BMI $(20 \mu \mathrm{M})$ and TTX $(1 \mu \mathrm{M})$ in the bath solution.

Inhibitory postsynaptic currents (IPSCs) were evoked at $-70 \mathrm{mV}$ by putting stimulating electrode positioned on the thalamic fiber path inside the BLA $(\sim 100 \mu \mathrm{m}$ from recording electrode) at a frequency of $0.05 \mathrm{~Hz}$ in the presence of CNQX $(20 \mu \mathrm{M})$ and AP5 $(100 \mu \mathrm{M})$, and verified by adding $\mathrm{GABA}_{\mathrm{A}}$ receptor antagonist BMI $(20 \mu \mathrm{M})$. The pipette (input resistance: $2-5 \mathrm{M} \Omega$ ) solution contained $140 \mathrm{mM} \mathrm{CsCl}$, $10 \mathrm{mM}$ Hepes, $0.2 \mathrm{mM}$ EGTA, $1 \mathrm{mM} \mathrm{MgCl}_{2}, 4 \mathrm{mM} \mathrm{Mg-}$ ATP, $0.3 \mathrm{mM} \mathrm{Na-GTP,} 10 \mathrm{mM} \mathrm{Na} \mathrm{Na}_{2}$-phosphocreatine and $5 \mathrm{mM}$ QX314 (pH 7.40, $285 \mathrm{mOsm}$ ). To record miniature IPSCs (mIPSCs), $1 \mu \mathrm{M}$ TTX was added in the bath solution. For outward IPSC recordings, because our preliminary experiments showed that the reversal potential for the IPSCs was close to $0 \mathrm{mV}$ (data not shown), we set the holding potential to $0 \mathrm{mV}$, conveniently. The pipette solution (input resistance: 3-6 M $\Omega$ ) contained $125 \mathrm{mM}$ Cs-methanesulfonate, $5 \mathrm{mM} \mathrm{CsCl}, 10 \mathrm{mM}$ Hepes, $0.2 \mathrm{mM}$ EGTA, $1 \mathrm{mM} \mathrm{MgCl}_{2}$, $4 \mathrm{mM}$ Mg-ATP, $0.3 \mathrm{mM}$ Na-GTP, $10 \mathrm{mM} \mathrm{Na} 2$ phosphocreatine and $5 \mathrm{mM}$ QX314 (pH 7.40, $285 \mathrm{mOsm})$. The stimulus intensity was varied systematically $(5,10,15,20,25,30,35$, 40 , and $45 \mu \mathrm{A})$, and was verified by adding BMI $(20 \mu \mathrm{M})$. In each cell, at least three responses of each intensity were averaged. Data were collected when the series resistance fluctuated within $20 \%$ of the initial values (10-20 M $\Omega$ ), filtered at $3 \mathrm{kHz}$, and sampled at $10 \mathrm{kHz}$.

The perfusion concentrations for electrophysiological recordings were as follows: $5 \mathrm{nM}$ NRG1, $1 \mu \mathrm{g}$ ecto-ErbB4, $5 \mu \mathrm{M}$ AG1478, and $10 \mu \mathrm{M}$ PD. 


\section{Intracerebral Infusions}

As previously reported (Rodriguez Manzanares et al, 2005), mice were anesthetized with an intraperitoneal injection of chloral hydrate $(400 \mathrm{mg} / \mathrm{kg})$ and placed into a stereotaxic instrument (Stoelting, USA). The mouse scalp was incised and retracted, and small burr holes (1 $\mathrm{mm}$ diameter) were drilled into the skull with a dental drill. Stainless-steel guide cannulas (Plastics One; C315G/SPC; length, $6 \mathrm{~mm}$ ) were lowered into the random and unilateral BLA using the following coordinates, anterior, $-1.5 \mathrm{~mm}$; lateral, $\pm 3.2 \mathrm{~mm}$; and ventral, $-4.7 \mathrm{~mm}$, according to The Mouse Brain in Stereotaxic Coordinates. The guide cannulas were secured in place using glass ionomer cements. Dummy cannulas (Plastics One; C315DC/SPC, with lengths matching the guide cannulas) were placed inside the guide cannulas to prevent occlusion. Incisions were fixed and covered with glass ionomer cement. The animals were removed from the stereotaxic instrument and recovered on an electric blanket, and then they were placed back into their home cages. The behavioral tests were performed 7days after surgery.

To execute local infusions into the BLA, the mice were restrained, and the dummy cannulas were removed quickly from the guide cannulas and replaced by infusion cannulas (Plastics One; C315I/SPC, with lengths matching the guide cannulas). Infusion cannulas were fitted into the guide cannulas. The infusion cannulas were connected, via polyethylene tubing (Plastics One; $\mathrm{C} 313 \mathrm{C}$ ) to $10 \mu \mathrm{l}$ microsyringes (Hamilton, Reno, NV) mounted on a microinfusion pump (RWD200, China). Each mouse was injected with $0.5 \mu \mathrm{l} /$ side at a flow rate of $0.25 \mu \mathrm{l} / \mathrm{min}$. This volume was selected according to the size and structure of these nuclei. To allow the diffusion of the drug, the infusion cannulas were kept in for 2 min before being replaced with the dummy cannulas. The injection concentrations were as follows: $100 \mathrm{nM}$ NRG1, $200 \mu \mathrm{g}$ ecto-ErbB4, $50 \mu \mathrm{M}$ AG1478, $10 \mu \mathrm{M}$ PD, and $0.2 \mathrm{mM}$ BMI.

\section{Viral Injection}

Viral vectors were produced as described in Davidson et al (2000) by University of Florida Research Foundation. The vectors were adeno-associated virus (AAV) that contained a truncated chimeric CMV-chicken $\beta$-actin (smCBA) promoter driving CRE and green fluorescent protein (GFP). The AAV-CRE vector contained an internal ribosomal re-entry site (IRES) after GFP and was followed by CRE.

As previously described (Coryell et al, 2008), the mice were anesthetized and placed in a stereotaxic frame. Viral vectors were AAV-CRE-GFP (titer $1 \times 10^{12} \mathrm{vg} / \mathrm{ml}$ ) and AAV-GFP (titer $\left.1 \times 10^{12} \mathrm{vg} / \mathrm{ml}\right)$. Virus $(0.5 \mu \mathrm{l})$ was infused using a $10 \mu \mathrm{l}$ Hamilton syringe with infusion cannulas and a microinjector pump at a rate of $0.2 \mu \mathrm{l} / \mathrm{min}$; the needle was kept in position for $3 \mathrm{~min}$ after injection. The injection coordinates were as described above. Mice were rested for 14 days before the next experiment.

\section{Behavioral Tests}

Elevated plus maze (EPM) test. The test consists of an elevated, plus-sign-shaped runway that was $\sim 40 \mathrm{~cm}$ above the floor, with two opposing wall-closed arms $(10 \times 50 \mathrm{~cm})$, with the other two arms $(10 \times 50 \mathrm{~cm})$ being open and having one intersection $(10 \times 10 \mathrm{~cm})$. Mice were allowed to acclimate to the testing room $30 \mathrm{~min}$ before the test. At the time of the test, each mouse was placed in the center of the EPM, where the four arms cross each other, facing the closed arm, and was videotaped for $5 \mathrm{~min}$. The time spent in the closed and open arms was quantified autonomously by the computational software.

Open field. The open field test was performed in a rectangular chamber $(60 \times 60 \times 40 \mathrm{~cm})$ that was made of gray polyvinyl chloride and was monitored by an automated video tracking system. The center area was illuminated by $25 \mathrm{~W}$ halogen bulbs $(200 \mathrm{~cm}$ above field). The mouse was gently placed on the center square for a 5-min period of recording. After each trial, the apparatus was swept out with water that contained $0.1 \%$ acetic acid. The following parameters of the digitized images of the path were automatically calculated using the DigBehv animal behavior analysis program: the time spent in the field centre zone, the distance moved, and the speed.

The social interaction test was performed as previously described (Adachi et al, 2009). The experiment consisted of two 5-min phases, and the movements of mice were recorded with a video tracking system using Ethovision software. In the pre- $5 \mathrm{~min}$ period, an experimental mouse was placed in one corner of the test box that contained a wire mesh cage located against the opposite walls. Immediately thereafter, the experimental mouse was removed from the box, and the target unfamiliar mouse was placed in the wire mesh cage. For the second $5 \mathrm{~min}$, the experimental mouse was then reintroduced into the test box. The wire mesh cage allowed visual and olfactory interaction between the mice but prevented direct body contact. The duration of the time spent in the interaction zone in the absence and presence of the unfamiliar target was measured, and the ratio was used as the interaction index.

Novelty-suppressed feeding (NSF) test. Before each test, a single pellet of food was placed on a white piece of paper platform positioned at the center of the testing box $(50 \times$ $50 \times 20 \mathrm{~cm}$ ), in which the floor was covered with $2-\mathrm{cm}$-thick padding. At $24 \mathrm{~h}$ after food deprivation, but not with water deprivation, mice were placed in a corner of the plastic box; after that, a stop-watch was immediately started to count to $5 \mathrm{~min}$. The scoring for the measure of the exploration latency did not begin until the mice received food with their forepaws and began biting (latency to bite the food). Immediately after the test, the mouse was transferred to its home cage, in which the amount of food consumed in the next $5 \mathrm{~min}$ was measured (home-cage food intake).

Restraint stress. In a room distinct from those used for anxiety-like behavioral testing, mice were placed in plastic tubes with numerous holes for a period of $1 \mathrm{~h}$. A reversible flapper was placed around the other end of the cylinder to prevent the mouse from backing out of the restrainer. Mice were then removed from the tubes and transported back to the home cage. Control mice were transported to the room distinct from those used for anxiety-like behavioral testing for $1 \mathrm{~h}$ without the restraint stress, and afterwards they were moved back to the home cage. 


\section{Histology}

Fluorescent immunohistochemistry was performed as previously described (Lerch-Haner et al, 2008). The following primary antibodies were used: rabbit anti-PV (Swant; 235; 1:1000 for staining); mouse anti-Calretinin (Swant; 6B3; 1:1000 for staining); mouse atni-Calbindin (Swant; 300; $1: 5000$ for staining), and goat anti-Somatostatin (Santa Cruz; SC-7819, 1:200 for staining). The secondary antibody was rhodamine-conjugated rat-absorbed donkey anti-sheep IgG (1:200; Jackson ImmunoResearch). For double labeling, slices were analyzed under a confocal microscope (Zeiss LSM 510). Fluorescent and bright-field images were collected using a SPOT RT color digital camera (Diagnostic Instruments) attached to an Olympus Optical BX51 microscope.

\section{Quantitative Real-Time PCR}

As previously reported (Liu et al, 2010), mice brain sample were dissected and prepared after selection. Different brain tissue was placed immediately in Trizol (Invitrogen), and RNA was extracted according to the manufacturer's manual. Genomic DNA was removed by gDNA eraser treatment (Takara), and $1 \mu \mathrm{g}$ RNA was used for first-strand cDNA synthesis (Takara). For real-time RT-qPCR, a SYBR detection system (Takara), specific primers (NRG1-F: 5'-ACCAGCCA TCTCATAAAGTGCG- $3^{\prime}$ and NRG1-R: $5^{\prime}$-TTGACGGGTTTG ACAGGTCC-3'; ErbB4-F: 5'-AGTGGTCTGTCATTGCTTAT CCTC- $3^{\prime}$ and ErbB4-R: 5'-CTGTTGTCCGTGATGTAGAT ATTGC- $3^{\prime}$ ), and $2 \mu \mathrm{l}$ of undiluted cDNA were used in $20 \mu \mathrm{l}$ PCR reactions. Each reaction was performed in duplicate. All real-time RT-PCR reactions were performed in 40 cycles on the iCycler (Agilent Technologies Stratagene Mx3005P). The relative gene expression and statistics analysis were determined using the Relative Expression Software Tool.

\section{Western Blot Analysis}

Mice were killed after selection. As described previously (Yan et al, 2010; Zhu et al, 2010), PFC, HPC, and AM tissue samples were prepared. Samples were subjected to electrophoresis in SDS-10\% polyacrylamide gels, and then they were transferred to polyvinylidene fluoride membranes. The membranes were blocked with 5\% nonfat milk and incubated overnight at $4{ }^{\circ} \mathrm{C}$ with antibodies: rabbit polyclonal antiErbB4 (SC283; 1:500; Santa Cruz Biotechnology), rabbit polyclonal anti-NRG1 (SC28916; $1: 500$; Santa Cruz Biotechnology), or monoclonal mouse anti- $\beta$-actin (1:1000; Bostor, China). On the second day, the membranes were incubated with secondary horseradish peroxidase-conjugated antibodies (GE Healthcare) and detected by the Quantitative Imaging SystemFluorChemSP (Alpha Innotech). The protein bands were analyzed with FluorChem SP software. Optical densities (ODs) were normalized to OD values for the corresponding $\beta$-actin on the same membrane.

\section{Statistical Analysis}

Data were presented as mean \pm SEM of three or more independent experiments. For multiple group comparisons, statistical differences were calculated by one-way ANOVA followed by Dunnett's test. For comparison of means from the same group of cells, Student's paired $t$-test was used. mIPSCs were analyzed by the Kolmogorov-Smirnov (K-S) test. Values of $p<0.05$ were considered significant.

\section{RESULTS}

NRG1 and ErbB4 Expression Levels in the Amygdala Differ Between High-Anxiety and Low-Anxiety Mice

Do anxiety-like behaviors depend on endogenous NRG1 and/or ErbB4 levels in the amygdala or other regions? We addressed this question by capitalizing on the previous studies that there can be considerable variability in the anxiety level across mice (Hugues and Garcia, 2007; Peters et al, 2010). Mice underwent tests of the EPM. 'Highanxiety' and 'low-anxiety' mice had anxiety values in the top or bottom 44\%, respectively (ie, the middle $12 \%$ was excluded). These two groups differed significantly on the test day (Figures 1a and b). For each subgroup, brain tissue from the cortex, amygdala, and hippocampus was dissected $24 \mathrm{~h}$ after the anxiety test to determine the NRG1 and ErbB4 levels.

The real-time quantitative fluorescence PCR analysis revealed that both the NRG1 and the ErbB4 mRNAs were significantly decreased in the amygdala of high-anxiety mice compared with the low-anxiety mice $(\mathrm{t}(6)=3.794$ and 4.61, $P=0.032$ and 0.019 , respectively; Figures $1 \mathrm{c}$ and d). At the same time, western blotting showed that the $65 \mathrm{KD}$ NRG1, 32KD-NRG1, and ErbB4 proteins were significantly decreased in the amygdala of high-anxiety mice compared with the low-anxiety mice $(\mathrm{t}(6)=3.745,3.961$ and 8.143, $P=0.033,0.029$ and 0.004 , respectively; Figures $1 \mathrm{e}-\mathrm{h})$. Although the NRG1 mRNA was increased in the hippocampus of high-anxiety mice $(\mathrm{t}(6)=-2.71, P=0.035$; Figure 1c), neither the NRG1 proteins nor the ErbB4 protein in the hippocampus changed significantly between the two groups $(\mathrm{t}(6)=0.302,1.28$ and $1.358, P=0.782,0.291$ and 0.267 , respectively; Figures if and h). Neither the mRNA nor the proteins of NRG1 and ErbB4 in the cortex were different between the two groups. These data indicate that there are anxiety-related differences in NRG1-ErbB4 expression in the amygdala, and downregulation of NRG1ErbB4 signaling might underlie the mechanism of the anxiogenic process.

\section{Neutralizing Endogenous NRG1 in the Amygdala Enhances Anxiety-Like Behaviors}

To further determine whether NRG1 modulates anxiety, we examined the effect of manipulating NRG1 activity in the BLA on anxiety-like behaviors that are a well-established function of the amygdala (Etkin et al, 2009; Hajizadeh Moghaddam et al, 2008; Muller et al, 1997; Scheel-Kruger and Petersen, 1982; Tye et al, 2011). Two strategies were used to alter the NRG1 activity, neutralization of endogenous NRG1 and administration of exogenous NRG1, and the following experiments were performed: guide cannulas were first implanted into normal healthy C57 mice BLA, and 1 week later, drug was infused through guide cannulas and then, after a 1-h interval, mice underwent one of the types of anxiety-like behavioral tests: the open field test, the EPM test, the social interaction test, and the NSF test (which 

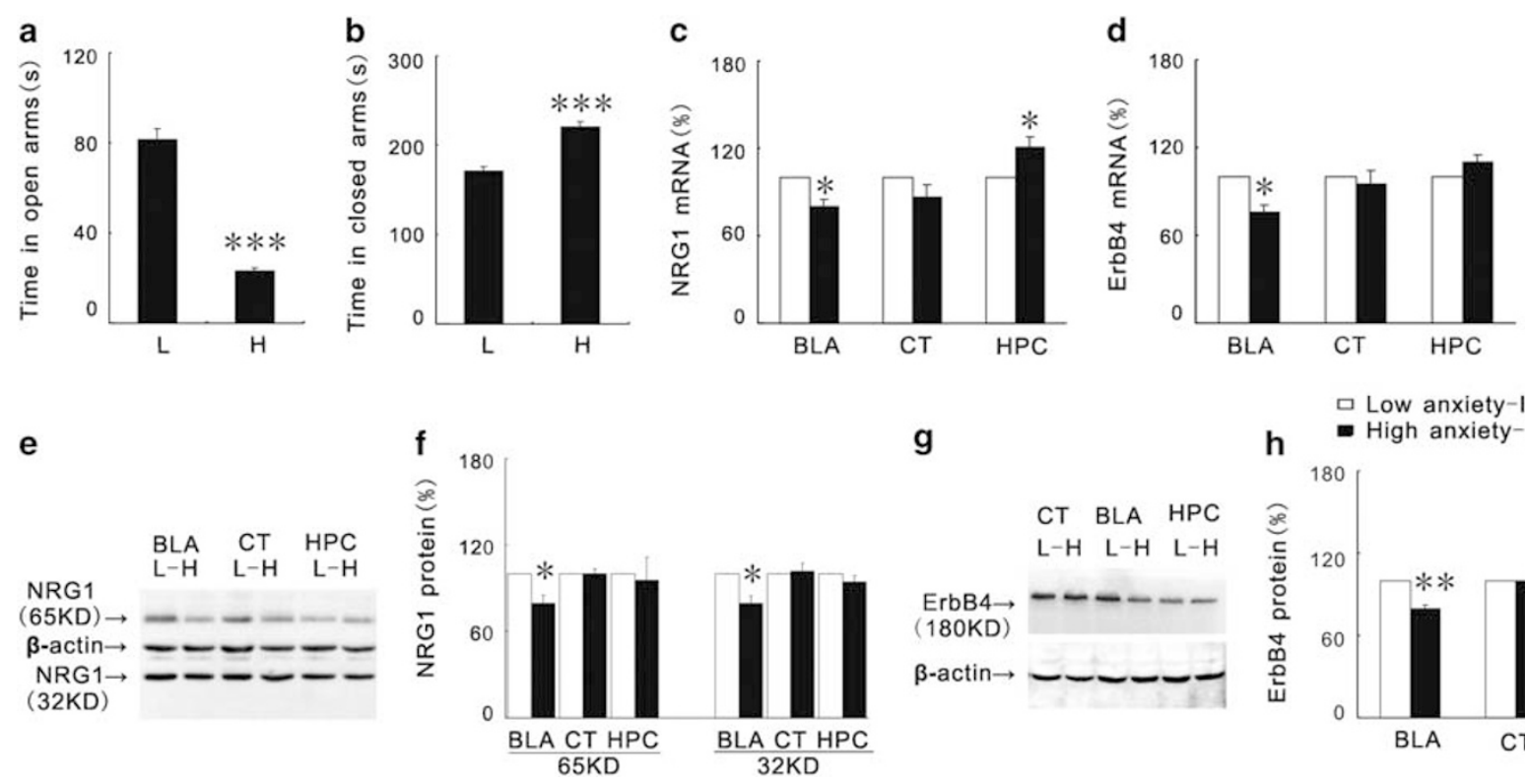

g

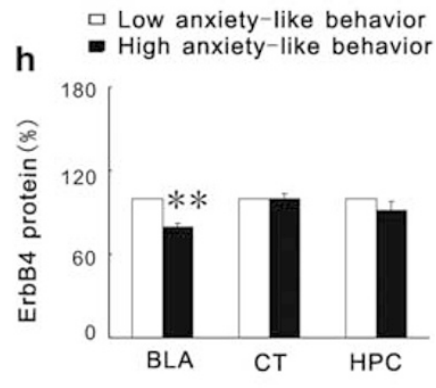

Figure I The NRGI and ErbB4 mRNA and protein expression levels in amygdala are different between the high-anxiety and low-anxiety mice. (a, b) After the elevated plus maze test, the mice were divided into high-anxiety-like behavioral and low-anxiety-like behavioral groups according to their anxiety levels. (c, d) The real-time quantitative fluorescence PCR analysis shows NRGI and ErbB4 mRNA expression. (e-h) Western blotting shows NRGI and ErbB4 protein expression. L, low-anxiety-like behavioral group; H, high-anxiety-like behavioral group; HPC, hippocampus; $\mathrm{CT}$, cortex. N=4/group. Twotailed $t$ test: $* P<0.05, * * P<0.01$, $* * * P<0.001$. Data are expressed as mean $\pm \mathrm{SEM}$.

entailed food deprivation for the previous $24 \mathrm{~h}$; Supplementary Figure 1a). To minimize the suffering of the mice, one batch of mice underwent all of the behavioral tests, and after each of the tests, mice were allowed to rest for 3-4 days.

To determine whether endogenous NRG1 regulates anxiety, we explored the consequences of sequestering NRG1 by administering a soluble form of polypeptide, ectoErbB4. This polypeptide contains the entire extracellular domain of ErbB4 and is known to bind to and sequester NRG1, thus preventing it from activating endogenous receptors (Woo et al, 2007). Moreover, previous studies report that the infusion of benzodiazepines or $\mathrm{GABA}_{\mathrm{A}}$ agonists in the BLA reduce anxiety (Muller et al, 1997; Scheel-Kruger and Petersen, 1982), whereas the $\mathrm{GABA}_{\mathrm{A}}$ antagonists increase anxiety(Hajizadeh Moghaddam et al, 2008); as a result, we used the $\mathrm{GABA}_{\mathrm{A}}$ receptor antagonist (Bicuculline (BMI)) as a positive control. In addition, we used boiled ecto-ErbB4 to exclude the possible proteininduced unspecific effects on the mice's behaviors. As shown in Supplementary Figure 1b, the spread of the drugs was limited into the BLA.

At $1 \mathrm{~h}$ after drug infusion through the guide cannulas, we performed the behavioral tests. No differences were observed in the locomotor activity, including in the total path and speed $\left(\mathrm{F}_{3,35}=0.078, P=0.972\right.$; Figures $2 \mathrm{a}$ and $\left.\mathrm{b}\right)$, among the different groups in the open field test. Both ectoErbB4 and the $\mathrm{GABA}_{\mathrm{A}}$ receptor antagonist $\mathrm{BMI}$ reduced the time spent in the central zone during $5 \mathrm{~min}$ of open field testing $\left(\mathrm{F}_{3,35}=17.514, P=0.004\right.$ and 0.003 , respectively; Figure 2c). The ecto-ErbB4 and BMI also decreased the social interaction behavior $\left(\mathrm{F}_{3,35}=18.695, P=0.001\right.$ and $<0.0001$, respectively; Figure 2d). In the EPM test, the ectoErbB4 and BMI groups showed significantly decreased time in the open arms $\left(\mathrm{F}_{3,35}=18.542, P=0.012\right.$ and 0.003 , respectively; Figure 2e) and increased time in the closed arms $\left(\mathrm{F}_{3,35}=4.605, P=0.235\right.$ and 0.002 , respectively; Figure $2 \mathrm{f}$ ), although the effect of ecto-ErbB4 on the closed arm time did not reach a significant level that might be because of more time spent in the central zone. In the NSF latency test, both ecto-ErbB4 and the BMI increased the latency time before biting the food $\left(\mathrm{F}_{3,35}=8.463, P=0.005\right.$ and $<0.0001$, respectively; Figure $2 \mathrm{~g}$ ) without affecting the food intake amounts $\left(\mathrm{F}_{3,35}=0.126, P=0.855\right.$ and 0.728 , respectively; Figure 2h). In contrast to ecto-ErbB4, the boiled ecto-ErbB4 showed no effects on all of the behaviors that were tested (Figures 2a-h).

Next, we investigated the effect of exogenous NRG1 on anxiety-like behaviors. As shown in Supplementary Figure 2, the infusion of exogenous NRG1 into the BLA does not affect normal mice's anxiety-like behaviors.

Together, we found that neutralizing endogenous NRG1 of the BLA enhanced anxiety-like behaviors, whereas infusion of exogenous NRG1 showed no effects, suggesting that NRG1 signaling in the amygdala is necessary for the modulation of anxiety-like behaviors and the activity of endogenous NRG1 might be at a saturated level in the amygdala of the normal mouse.

\section{ErbB4 in the Amygdala Is Critical for the Modulation of Anxiety-Like Behaviors}

To determine whether ErbB4 in the amygdala is critical for the modulation of anxiety-like behaviors, we infused the ErbB4 antagonists PD158780 (PD) and AG1478 into the BLA. The DMSO (the solvent for AG1478 and PD, $<0.1 \%$ in ACSF) was used as a control to exclude the possible effect of DMSO on mice behaviors. At $1 \mathrm{~h}$ after drug infusion 


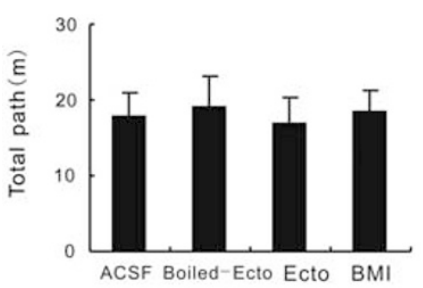

e

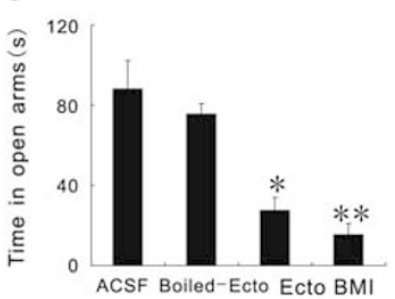

b

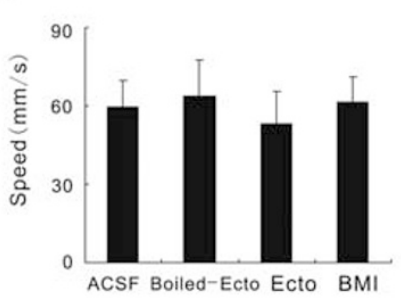

f

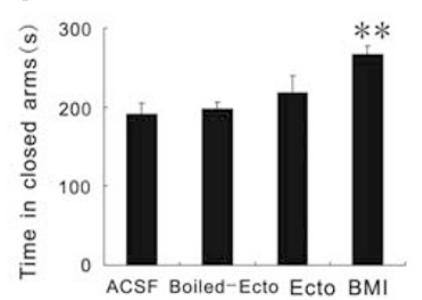

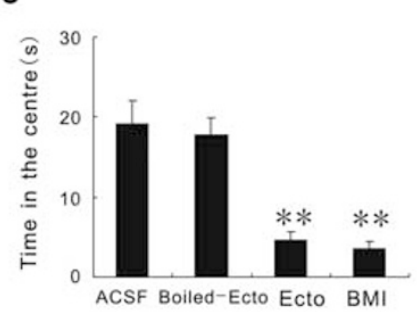

g

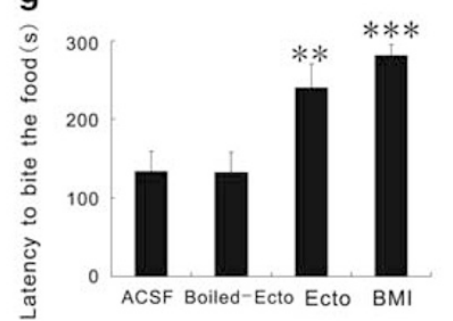

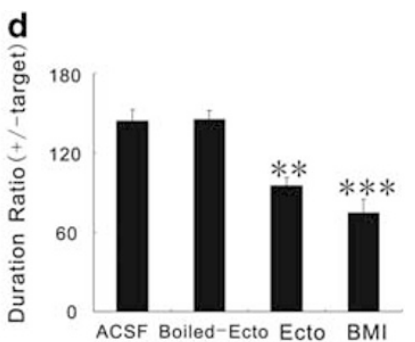

h

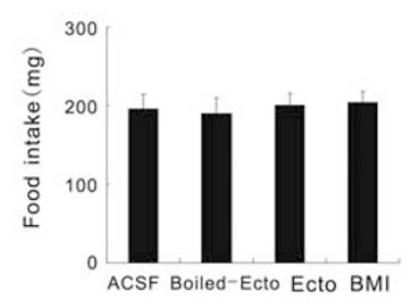

Figure 2 Anxiety-like behaviors are enhanced by neutralizing endogenous NRGI with ecto-ErbB4 (Ecto) in the amygdala. (a, b) Distance traveled or speed was not different among the different groups in the open field test. (c) The Ecto and BMI groups showed increased anxiety-like behavior that was measured by the time spent in the central arena in the open field test. (d) The Ecto and BMI groups showed less interaction with novel mice in the social interaction test. (e, f) In the elevated plus maze test, mice treated with Ecto or BMI spent significantly less time in the open arms and more time in the closed arms. (g, h) The novelty-suppressed feeding latency test showed increased anxiety in the Ecto and BMI groups, with no appetite difference. ACSF, $n=9$; boiled Ecto, $n=10$; Ecto, $n=1$ I; BMI, $n=9$. One-way ANOVA/LSD post hoc test: $* P<0.05$, *** $P<0.01$, **** $P<0.00$ I. Data are expressed as mean \pm SEM.

through guide cannulas that were implanted into the BLA 1 week earlier, we found that inhibiting the ErbB4 receptor with the AG1478 and PD reduced the time that was spent in the central region of the open field $\left(\mathrm{F}_{3,37}=14.73, P=0.001\right.$ and $<0.0001$, respectively; Figure $3 \mathrm{c}$ ) without impaired locomotion $\left(\mathrm{F}_{3,37}=0.153, P=0.767\right.$ and 0.689 , respectively; Figures $3 \mathrm{a}$ and $\mathrm{b})$. AG1478 and PD also decreased the social interaction ratio that reflects the social anxiety behavior $\left(F_{3,37}=15.087, P=0.009\right.$ and $<0.0001$, respectively; Figure $3 \mathrm{~d})$. In the EPM experiment, compared with the control group, the AG1478 and PD groups showed less time in the open arms $\left(F_{3,37}=4.567, P=0.035\right.$ and 0.002 , respectively; Figure $3 \mathrm{e}$ ) and more time in the closed arms $\left(\mathrm{F}_{3,37}=7.184, P=0.37\right.$ and 0.002 , respectively; Figure $\left.3 \mathrm{f}\right)$, although the effect of AG1478 in the closed arms was not significant. The same anxiogenic effect was observed in the NSF latency test. Both AG1478 and PD made the latency of exploring food longer $\left(\mathrm{F}_{3,37}=40.104\right.$, both $\mathrm{P}<0.0001$; Figure $3 \mathrm{~g}$ ) and, at the same time, did not affect the appetite $\left(\mathrm{F}_{3,37}=0.215, P=0.482\right.$ and 0.578 , respectively; Figure $\left.3 \mathrm{~h}\right)$. These observations suggest that there is an involvement of ErbB4 in the regulation of anxiety-like behaviors.

Because AG1478 and PD are pan-ErbB-specific antagonists that target the intracellular tyrosine phosphorylation sites of these receptors, we next used adeno-associated virus that expressed CRE recombinase (AAV-GFP-CRE) to specifically delete loxP-flanked chromosomal ErbB4 DNA sequences of the ErbB4-loxp mice and, at the same time, used the AAV-GFP vehicles with no CRE expression as the control treatment. At 2 weeks after bilateral injection of AAV-GFP-CRE and AAV-GFP into the BLA of the ErbB4loxp mice, the western blot showed the successfully knocked down ErbB4 protein in the BLA region (Figure $4 a$ ) with the anti-ErbB4 antibody. The tissue from the ErbB4 knockout mice ('mutant' band) was used to show the specificity of the anti-ErbB4 antibody. After confirming the BLA deletion of ErbB4, we examined the effects of this inducible deletion on a number of anxiety-like behavioral tasks. ErbB4 knockdown mice were similar to the control mice in the locomotor function $(\mathrm{t}(23)=0.098, P=0.922$; Figures $4 \mathrm{~b}$ and c), but they showed a significantly decreased time in the central zone of the open field test $(\mathrm{t}(23)=3.619, P=0.001$; Figure $4 \mathrm{~d})$. The anxiogenic effect was also observed in the social interaction test $(\mathrm{t}(23)=2.512, P=0.019$; Figure $4 \mathrm{e})$. In the EPM test, knockdown of ErbB4 significantly reduced the time that was spent in the open arms $(\mathrm{t}(23)=2.086$, $P=0.048$; Figure 4f) and increased the time in the closed arms $(\mathrm{t}(23)=-2.992, P=0.007$; Figure $4 \mathrm{~g})$. Moreover, the NSF latency test showed that ErbB4 deletion increased the latency to bite the food $(\mathrm{t}(23)=-3.6, P=0.003$; Figure $4 \mathrm{~h})$ without affecting the food intake appetite $(\mathrm{t}(23)=0.506$, $P=0.617$; Figure $4 \mathrm{i}$ ). These observations thus confirmed the conclusion that ErbB4 in the amygdala is necessary for the regulation of anxiety-like behaviors.

\section{NRG1-ErbB4 Signaling Does Not Modulate Glutamatergic Receptor-Mediated Synaptic Responses in the Amygdala}

The above results demonstrate that downregulation of NRG1-ErbB4 signaling in the amygdala enhances anxietylike behaviors that could be mediated by altered glutamatergic transmission or changed GABAergic transmission. Thus, we first checked the effect of NRG1-ErbB4 on EPSCs in pyramidal neurons of the amygdala in a whole-cell configuration. Evoked EPSCs (eEPSCs) were evoked by stimulation of the internal capsule fibers (thalamic input) and were recorded in pyramidal neurons in the basolateral 
a

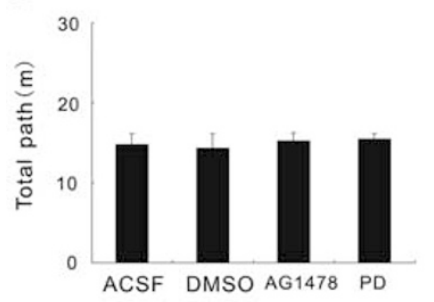

e

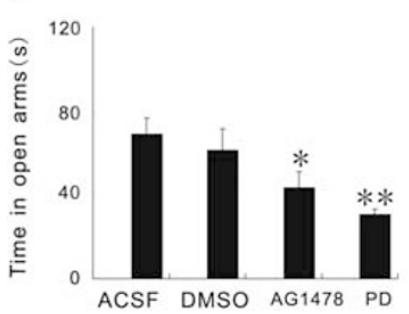

b

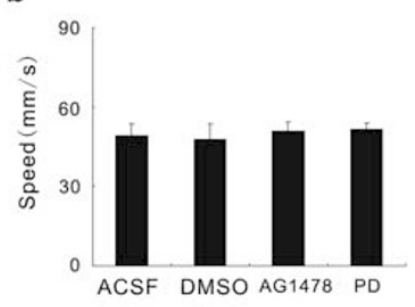

f

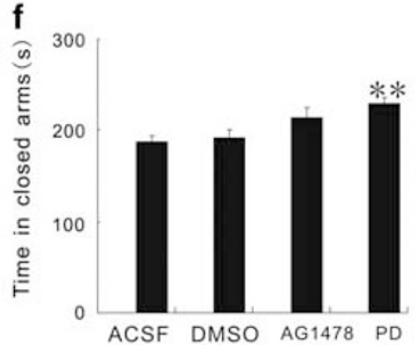

c

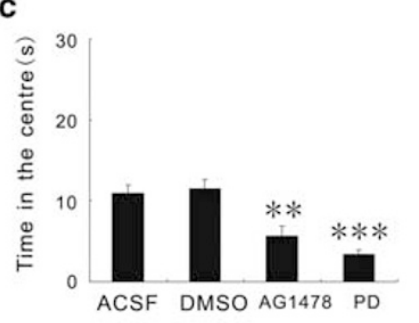

g

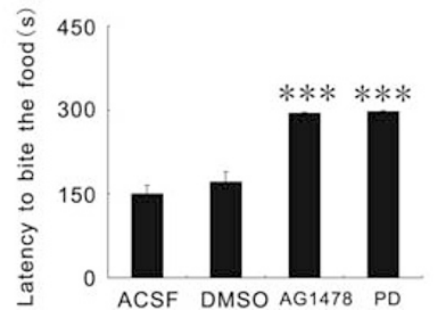

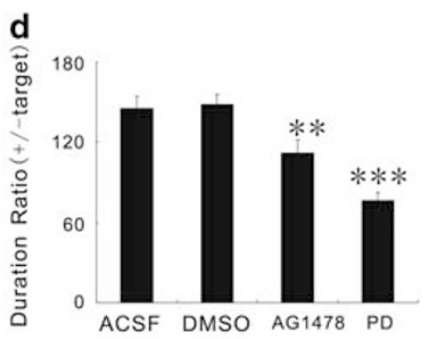

h

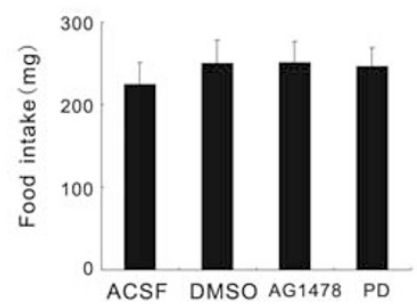

Figure 3 Inhibiting ErbB4 receptor in the amygdala increases anxiety-like behaviors. (a, b) The distance traveled and speed were not different among the drug treatment groups in the open field test. (c) The ErbB4 receptor antagonists the AGI478 and the PD groups showed increased anxiety-like behaviors in the open field test. (d) ErbB4 receptor antagonist groups showed less interaction with unfamiliar mice in the social interaction test. (e, f) In the elevated plus maze test, ErbB4 receptor antagonists increased the anxiety, as shown by the decreased time spent in the open arms and the increased time in the closed arms. $(\mathrm{g}, \mathrm{h})$ The novelty-suppressed feeding latency test showed increased anxiety in the ErbB4 receptor antagonist groups, with no appetite differences. ACSF, $n=10$; DMSO (solvent for AGI478 and PD), $n=10$; AGI478, $n=11 ; P D, n=10$. One-way ANOVA/LSD post hoc test. *P $<0.05$, *** $<0.01$, **** $P<0.00$ I. Data are expressed as mean \pm SEM.
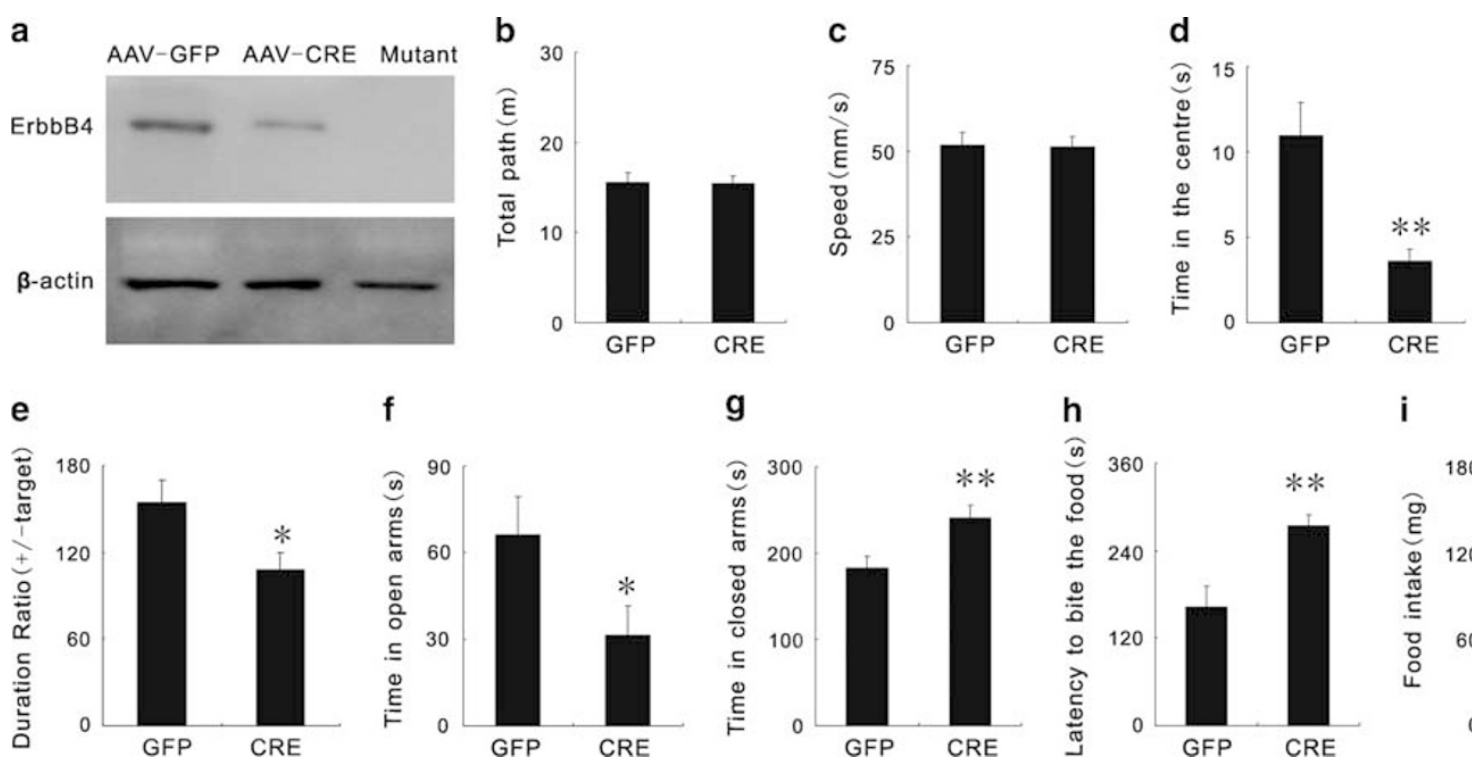

i

Figure 4 Knocking down ErbB4 receptor in the amygdala increases anxiety-like behaviors. (a) Western blotting showed that amygdala ErbB4 was downregulated by injecting AAV-GFP-CRE vectors into ErbB4-loxp mice. (b, c) The locomotor activity was not changed by knocking down ErbB4 in the open field test. (d) The ErbB4 knockdown group showed increased anxiety-like behavior in the open field test. (e) Knocking down ErbB4 induced anxiety in the social interaction test. $(f, g)$ In the elevated plus maze, knocking down ErbB4 significantly decreased the time spent in the open arms and increased the time spent in the closed arms. (h, i) The novelty-suppressed feeding test showed increased anxiety in the ErbB4 knockdown group, with no appetite changes, compared with the control group. AAV-GFP, $n=12$; AAV-GFP-CRE, $n=13$. Two-tailed t-test: $* P<0.05$, $* * P<0.01$, $* * * P<0.001$. Data are expressed as mean \pm SEM.

amygdala. As shown in Supplementary Figures 3a and b, AMPAR-mediated eEPSCs did not change after NRG1, ectoErbB4, or AG1478 treatments $(P=0.133,0.874$, and 0.198 , respectively), and neither did NMDAR-mediated eEPSCs in
Supplementary Figures $3 c$ and $d(P=0.864,0.666$, and 0.950 , respectively). Moreover, no changes were observed $10 \mathrm{~min}$ after washout. Finally, we measured miniature excitatory postsynaptic currents (mEPSCs) from the BLA 
pyramidal neurons to test whether NRG1-ErbB4 affects the spontaneous synaptic transmission. Both the amplitudes and frequencies of the mEPSCs were not changed by NRG1, Ecto-ErbB4, or AG1478 (for amplitudes: $P=0.300,0.095$, and 0.845 , respectively; for the frequencies: $P=0.325,0.970$, and 0.141 , respectively; Supplementary Figures $3 \mathrm{e}-\mathrm{m})$. Together, these observations demonstrate that the glutamatergic transmission at the amygdala synapses might not be regulated by NRG1-ErbB4 pathway.

\section{NRG1-ErbB4 Signaling Is Critical to Maintain GABAergic Activity in the Amygdala}

Having ruled out a possible effect on the glutamatergic transmission, we next tested whether the NRG1-ErbB4 pathway can regulate GABAergic transmission in the amygdala. IPSCs were recorded in pyramidal neurons of the amygdala in a whole-cell configuration. Evoked IPSCs (eIPSCs) were recorded in pyramidal neurons in the basolateral amygdala. The eIPSC amplitudes were not changed in NRG1-treated slices compared with the control, but they were decreased by eco-ErbB4 and AG1478 that could be reversed $10 \mathrm{~min}$ after washout $(P=0.313,0.003$, and 0.006 , respectively; Figures $5 \mathrm{a}$ and $\mathrm{b})$. These results suggest that GABAergic activity in the amygdala is controlled by endogenous NRG1/ErbB4 and further support the conclusion that NRG1 activity could be at a saturated level in this region of the normal mouse. Next, to investigate the presynaptic or postsynaptic mechanism that is involved in the regulation of GABAergic transmission by NRG1ErbB4, mIPSCs were measured at the amygdala pyramidal neurons. Neither NRG1 nor ecto-ErbB4 nor AG1478 produced an effect on the mIPSC amplitudes $(P=0.110$, 0.959, and 0.404, respectively; Figures $5 c$ and d; Supplementary Figure 4). Although NRG1 had no effect on the frequencies, the inhibitors Ecto-ErbB4 and AG1478 decreased the frequencies significantly $(P=0.361,0.001$, and $<0.001$, respectively; Figures $5 c$ and e; Supplementary Figure 4). In addition, these effects could be reversed $10 \mathrm{~min}$ after washout (Figure 5c). These results suggest that NRG1ErbB4 could promote GABAergic transmission by increasing the GABA release from the presynaptic terminals.

To further confirm the involvement of NRG1-ErbB4 in the modulation of GABAergic transmission, we measured eIPSCs under different intensities of the stimulus that ranged from 0 to $45 \mu \mathrm{A}$ in the amygdala slices from knocking down ErbB4 mice (Figure 5f). Knocking down ErbB4 decreased the amplitude of the eIPSCs significantly under stimulus intensities that ranged from 20 to $45 \mu \mathrm{A}$ $\left(\mathrm{F}_{1,24}=35.31, P<0.0001\right.$; Figure $\left.5 \mathrm{~g}\right)$.

Thus far, there is no direct or affirmative morphological evidence to explain why ErbB4 acts specifically through GABAergic neurotransmission in the BLA. To clarify this issue, we investigated whether ErbB4 is expressed specifically in the interneurons in the BLA by using transgenic mice to analyze the colocalization of ErbB4-positive neurons and GAD67-positive neurons. ErbB4-2A-CreERT2 mice express tamoxifen-inducible Cre-recombinase under the control of the ErbB4 gene (Madisen et al, 2010; Shamir et al, 2012), faithfully indicating the expression patterns of endogenous ErbB4. They were crossed with Ai14 mice that carry in the Rosa 26 locus, a CAG-driven red fluorescent protein variant (tdTomato) whose transcription was inhibited by a loxP-flanked stop cassette (Lakso et al, 1992). The resulting ErbB4-2A-CreERT2;Ai14 mice were injected with tamoxifen to release the stop signal and thus induce tdTomato expression. Figure $5 \mathrm{~h}$ shows the co(immuno)fluorescence micrograph image of tdTomato (red) that reports ErbB4 expression and endogenous GAD67(green) in the amygdala. The quantitative analysis showed that a large number of the ErbB4-expressing cells in the BLA coexpress GAD67 (98.99 $\pm 0.68 \%$ Figure 5i), although $54.22 \pm 2.39 \%$ GAD67-positive cells colocalized with ErbB4-expressing cells. These results provide immunohistochemical evidence that almost all of the ErbB4 in the BLA were expressed in GABAergic neurons, consistent with the electrophysiological results.

The subclasses of GABA interneurons are important for differential control of emotional behaviors, and we next investigated what subtypes of GABA interneurons expressed ErbB4. We stained amygdala sections of tdTomato (red)-expressing mice that report ErbB4 expression with antibodies for parvalbumin (green), calretenin (green), calbindin (green), or somatostatin (green) (Supplementary Figure 5). Quantitatively, 74\% of parvalbumin interneurons, $87 \%$ of calretenin interneurons, $38 \%$ of calbindin interneurons, and $21 \%$ of somatostatin interneuron were ErbB4 positive. On the other hand, most of ErbB4-positive neurons colocalized with parvalbumin interneurons, calretenin interneurons, and calbindin interneurons, and only $2 \%$ ErbB4-positive neurons colocalized with somatostatin interneurons. Taken together, these observations suggest that NRG1-ErbB4 could regulate the anxiety-like behavior through GABAergic transmission.

\section{Exogenous NRG1 Alleviates the Anxiety Susceptibility and Stress-Induced Anxiety}

To verify the above hypothesis, we tested whether exogenous NRG1 would reverse the anxiety-like behaviors of high-anxiety mice. Mice were implanted with guide cannulas in the BLA, and 1 week later, they underwent one of the behavioral tests: the open field test, the social interaction test, the EPM test, and the NSF latency test. Afterward, the 'high-anxiety' and 'low-anxiety' mice had an anxiety evaluation in the top or bottom $44 \%$ respectively (ie, the middle $12 \%$ was excluded) (Supplementary Figure 6). On the next day, subsequent drug treatment was performed on the high-anxiety mice: high-anxiety mice injected with ACSF (Control); high-anxiety mice injected with NRG1 (NRG1); high-anxiety mice injected with $\mathrm{NRG1}+\mathrm{PD}$ (NRG1 + PD); and high-anxiety mice injected with NRG1 + BMI (NRG1 + BMI). Anxiety-like behaviors were then measured again after the drug infusion.

As shown in Figure 6, infusion of NRG1 into BLA could significantly alleviate the high-anxiety-like behavior that was indicated by the open field test compared with the control group (NRG1 versus Control: $\mathrm{F}_{3,42}=28.750, P<0.0001$; Figure $6 \mathrm{c})$, without affecting the locomotor activity $\left(\mathrm{F}_{3,42}=\right.$ $0.004, P=0.911$; Figures $6 \mathrm{a}$ and $\mathrm{b})$. In addition, this anxiolytic effect was blocked by ErbB4 inhibitor PD and $\mathrm{GABA}_{\mathrm{A}}$ receptor antagonist (BMI) (control versus NRG1 + PD and NRG1+BMI: $F_{3,42}=28.750, \quad P=0.933, \quad 0.235$, respectively; Figure $6 \mathrm{c}$ ), suggesting that ErbB4 and $\mathrm{GABA}_{\mathrm{A}}$ 
a

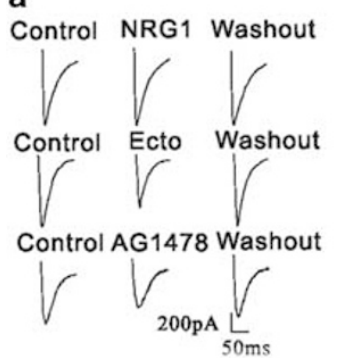

C

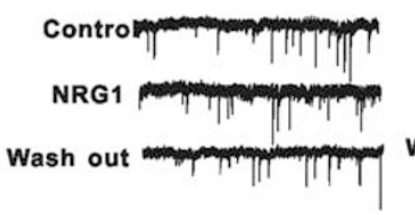

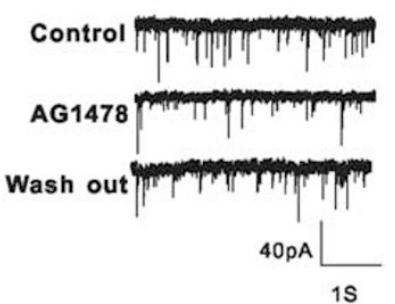

b

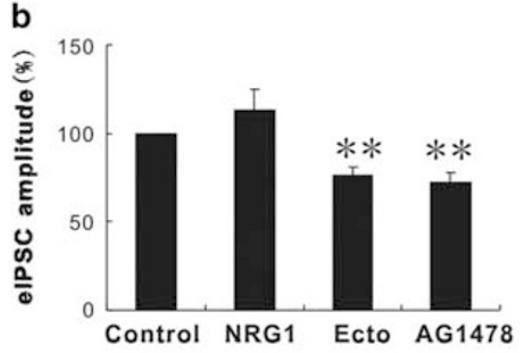

f

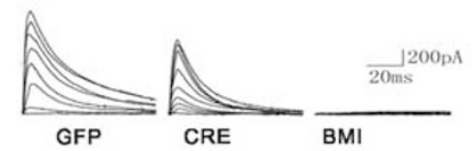

g

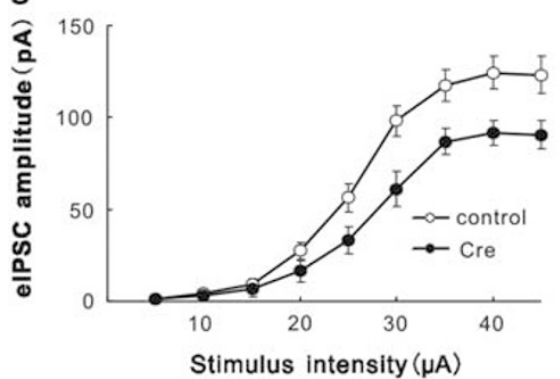

d

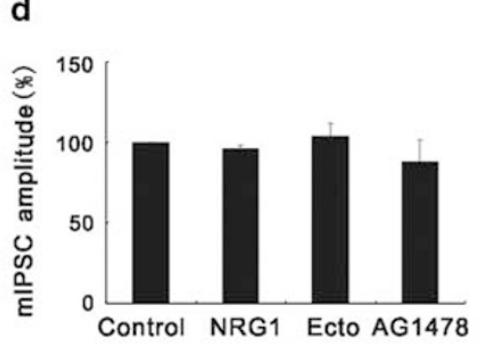

h
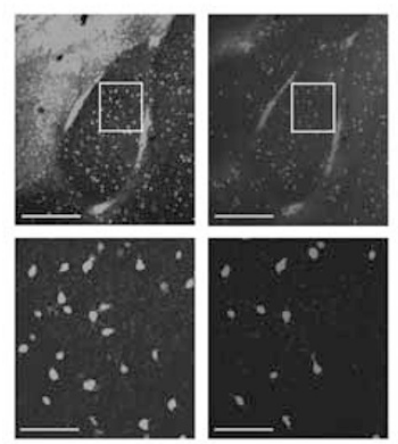

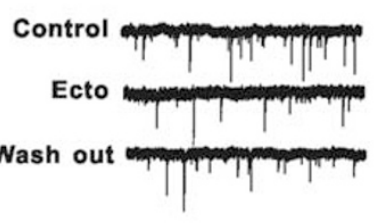

e

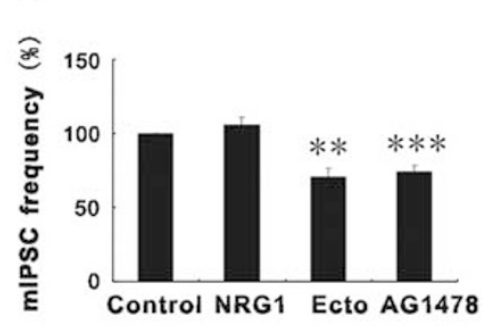

i
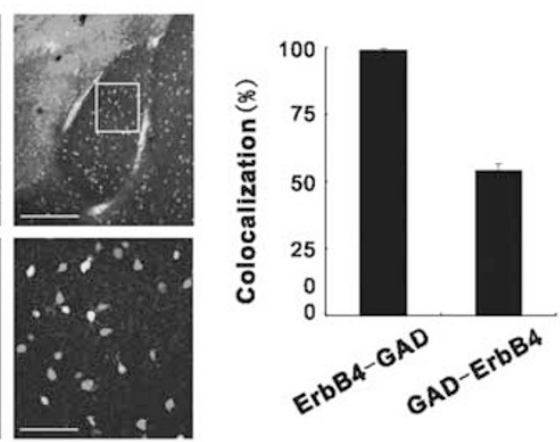

Figure $5 \mathrm{GABA}_{A}$ receptor-mediated synaptic currents are regulated by NRGI-ErbB4 signaling in the amygdala. (a) Shown are representative traces of eIPSCs. (b) NRGI had no effect on the peak amplitudes of the elPSC currents, but ecto-ErbB4 and AGI 478 decreased the elPSCs; $n=5$ for the AGI 478 treatment group, $n=6$ for the control, NRGI, and ecto-ErbB4 groups. (c) Shown are representative traces of mIPSCs. (d) Summarized data of mIPSCs showed no effect of drugs on mIPSC amplitudes in the pyramidal neurons in amygdala slices. (e) NRGI had no effect on the frequencies of the mIPSCs in the amygdala pyramidal neurons, but ecto-ErbB4 and AGI478 could decrease the frequencies; $n=6$ for the control and NRGI groups and $n=8$ for the ecto-ErbB4 and AGI 478 groups. (f, g) elPSCs were significantly decreased under the stimulus intensity from 0 to $45 \mu \mathrm{A}$ in ErbB4 knockdown amygdala slices. (h) Co(immuno)fluorescence micrograph image of tdTomato (red), reporting ErbB4 expression in adult Ail 4_ErbB4-2A-CreERT2 mice, and endogenous GAD67(green) in the amygdala. The boxed area is magnified in the lower panel. (i) Quantitative analysis showed a large number of the ErbB4-expressing cells in the BLA coexpress GAD67. GFP, $n=12 ;$ CRE, $n=14$. One-way ANOVA/LSD post hoc tests are for the data (b-d); two-way ANOVA for the data (g); independent $t$-test for the data (i). ${ }^{*} * P<0.01$, **** $P<0.00 \mathrm{I}$. Data are expressed as mean $\pm \mathrm{SEM}$.

receptors are involved in the NRG1-mediated reduction of innate fear. A similar phenomenon was observed in the social interaction test, the EPM test, and the NSF test. NRG1 treatment increased the social interaction of high-anxiety mice that was blocked by $\mathrm{PD}$ and $\mathrm{BMI}$ (control versus each group: $\mathrm{F}_{3,42}=4.196, P=0.003,0.545$, and 0.622 , respectively; Figure $6 \mathrm{~d}$ ). In the EPM test, NRG1 increased the time spent by high-anxiety mice in the open arms $\left(\mathrm{F}_{3,42}=6.796\right.$, $P=0.006)$ and decreased their time in the closed arms $\left(\mathrm{F}_{3,42}=4.427, P=0.003\right)$, both of which were counteracted by $\mathrm{PD}$ and $\mathrm{BBC}$ (Figure 6e). Without affecting the appetite (each group versus control: $\mathrm{F}_{3,42}=0.169, P=0.805,0.85$, and 0.647 , respectively; Figure $6 \mathrm{~g}$ ), NRG1 could reduce the latency to explore the food, and this effect was blocked by
ErbB4 receptor and $\mathrm{GABA}_{\mathrm{A}}$ receptor antagonists as well (each group versus control: $\mathrm{F}_{3,42}=5.541, P=0.004,0.833$, and 0.669 , respectively; Figure $6 \mathrm{f}$ ). Together, these results demonstrate that the infusion of exogenous NRG1 into BLA could significantly alleviate the high-level anxiety-like behaviors, although it had no effect on the anxiety-like behaviors of normal mice.

Next, we wondered whether the amygdala IPSCs could also be modulated by NRG1 in high-anxiety mice, even though this relationship did not occur in normal mice. To address this issue, we measured IPSCs in the BLA of highanxiety mice. The eIPSC amplitudes were increased in NRG1-treated slices compared with controls $(\mathrm{t}(10)=$ $-4.35, P=0.003$ ) that could be reversed $10 \mathrm{~min}$ after 
a

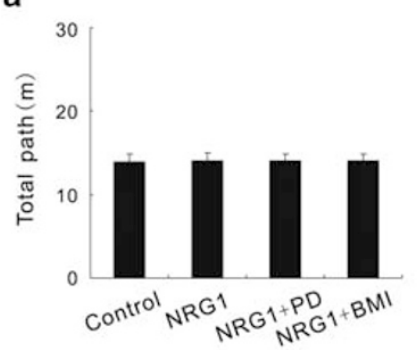

e

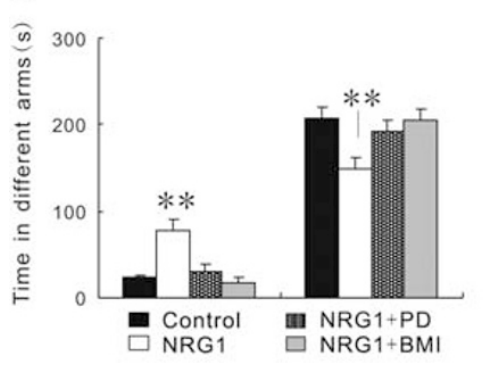

b

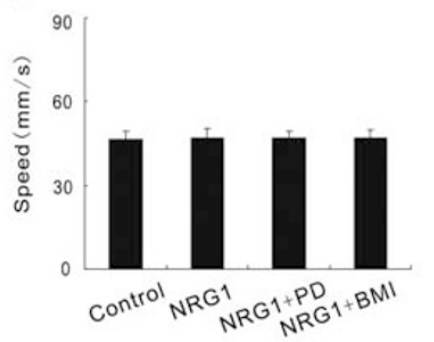

f

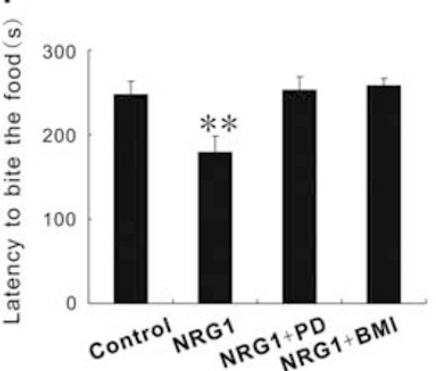

c

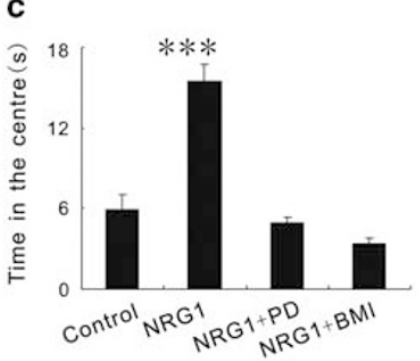

g

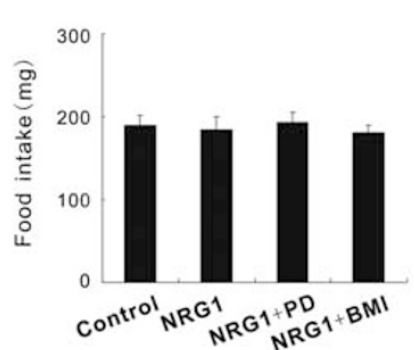

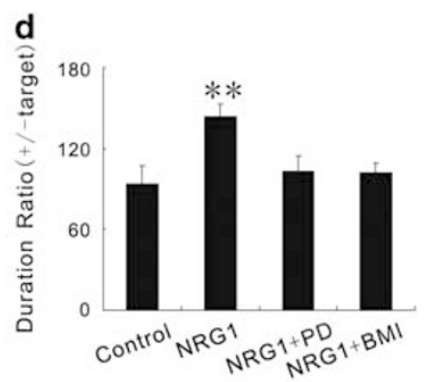

h

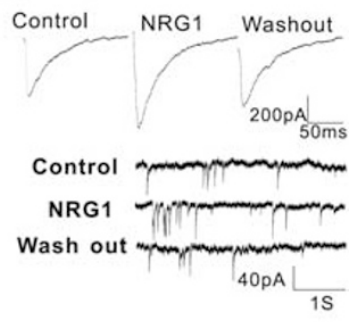

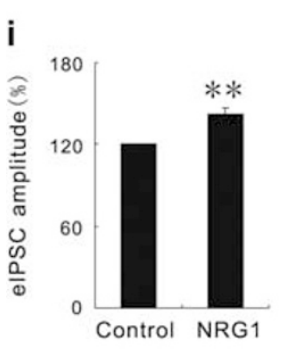

j

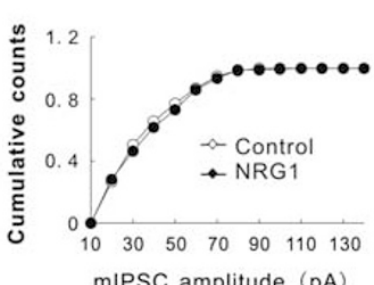

k

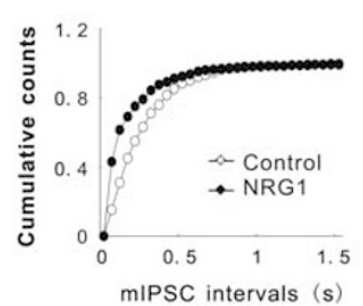

I

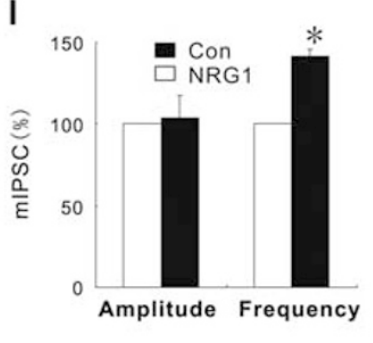

Figure $6 \mathrm{NRG}$ I alleviates the anxiety by acting on ErbB4 receptors and promoting the GABA release in high-anxiety mice. We firstly selected relatively high-anxiety mice from normal C57 mice (Supplementary Figure 6), and we performed experiments as follows: (a, b) Locomotor activity was not changed by different drug treatments in the open field test. (c) Injecting NRGI into the amygdala reduced high-anxiety-like behavior in the open field test that could be blocked by the ErbB4 antagonist or the GABA receptor antagonist. The same results were observed in the social interaction test (d), the elevated plus maze test (e), and the novelty-suppressed feeding test (f). (g) No difference was shown in the appetite of the different groups. Control, high-anxiety mice injected with ACSF, $n=1$ I; NRGI, high-anxiety mice injected with NRGI, $n=1$;; NRGI + PD, high-anxiety mice injected with NRGI + PD, $n=\mid 2$; NRGI + BMI, high-anxiety mice injected with NRGI + BMI, $n=12$. (h) Shown are representative traces of elPSCs and mIPSCs. (i, l) NRGI could increase the peak amplitude of the eIPSCs and the frequency of the mIPSCs in the amygdala slices of high-anxiety mice, but had no effect on the amplitude of the mIPSCs. (j) Cumulative plots of the mIPSC amplitudes. ( $k$ ) Cumulative plots of the mIPSC frequencies; $n=8$ for the elPSC groups AND $n=6$ for the mIPSC groups. One-way ANOVA/LSD post hoc test for data $(\mathrm{a}-\mathrm{g})$, independent $t$-test for data $(\mathrm{h}-\mathrm{I})$. $* P<0.05, * * P<0.0 \mathrm{I}$, ***P<0.00I. Data are mean \pm SEM.

washout (Figures $6 \mathrm{~h}$ and i). These results indicate that exogenous NRG1 could modulate eIPSCs only in highanxiety mice. Next, we investigated the presynaptic or postsynaptic mechanism that is involved in the regulation of GABAergic transmission by NRG1. The mIPSCs were measured at BLA pyramidal neurons. NRG1 produced no effect on the mIPSC amplitude $(\mathrm{t}(10)=-0.977, P=0.374$; Figures $6 j$ and 1 ) but increased the frequencies significantly $(\mathrm{t}(10)=-3.067, P=0.028$; Figures $6 \mathrm{k}$ and $\mathrm{l})$. In addition, these effects could be reversed $10 \mathrm{~min}$ after washout (Figure 6h). The above results suggest that exogenous NRG1 could increase the GABA release from presynaptic terminals in the BLA of high-anxiety mice, whose endogenous NRG1 and ErbB4 levels were downregulated.

To further investigate whether NRG1 is relevant for stress-induced anxiety, we designed the experiment as Supplementary Figure $7 \mathrm{a}$. We found that $1 \mathrm{~h}$ of restraint stress could induce increased anxiety-like behaviors, and infusion of exogenous NRG1 into BLA could reverse this anxiogenic effect (Supplementary Figure 7). In summary, the results reveal that NRG1 is also important for the modulation of acute stress-induced anxiety.

\section{DISCUSSION}

GABAergic mechanism in the amygdala, acting through the $\mathrm{GABA}_{\mathrm{A}}$ receptor, involves in the modulation of fear and anxiety (Flores-Gracia et al, 2010; Hajizadeh Moghaddam et al, 2008; Sanders and Shekhar, 1995). It has been proposed that the GABA activity in the amygdala has a critical role in maintaining lower firing rate of pyramidal neurons (Abe et al, 2011; Fox and Kornblum, 2005), presumably to enable animals to respond to appropriate sensory signals. Blockade of $\mathrm{GABA}_{\mathrm{A}}$ receptors in the BLA leads to increased anxiety responses (Sanders and Shekhar, 
1995). However, in contrast to cortex and hippocampus, regulatory mechanisms of GABAergic activity in the amygdala are not well understood. Here we explore the neural signaling pathway controlling the GABAergic neurotransmission and anxiety-related behaviors.

We found, for the first time to our knowledge, that the NRG1-ErbB4 signaling in the amygdala was critical for modulating anxiety-like behaviors through GABAergic neurotransmission. Almost all ErbB4 in the BLA were found to be expressed in GABAergic neurons. Blocking NRG1-ErbB4 signaling enhanced anxiety-like behaviors and, at the same time, inhibited GABA release. In contrast, exogenous NRG1 produced no effects on these behaviors and the synaptic transmission, suggesting that there was a saturated level of endogenous NRG1 in the amygdala. The expression level of both NRG1 and ErbB4 was downregulated specifically in the amygdala of high-anxiety mice, and the administration of NRG1 alleviated their anxiety and enhanced the GABAergic neurotransmission. In addition, an anxiolytic effect of NRG1 was also observed in the stressed mice. Together, our findings reveal that there is a novel function of NRG1-ErbB4 signaling in the regulation of anxiety-like behaviors that could provide a new perspective for treating anxiety disorders.

\section{The Amygdala NRG1-ErbB4 in the Regulation of Anxiety-Like Behaviors}

Both NRG1 and ErbB4 are expressed in the developing and adult brain (Garcia et al, 2000; Huang et al, 2000; Woo et al, 2007). Although NRG1 plays an important role in neuron migration, neurite outgrowth, cell differentiation, synapse formation, and schizophrenia (Mei and Xiong, 2008), few studies have focused on its role in innate fear-related behaviors. In our paper, we attempt to explore this scientific issue.

It has been proposed that the amygdala is critical for processing fearful emotions and anxiety (Hajizadeh Moghaddam et al, 2008; LeDoux, 2000; Muller et al, 1997; Scheel-Kruger and Petersen, 1982; Zarrindast et al, 2008). Extensive evidence also reveals that the GABAergic activity of BLA has been involved in the modulation of anxiety (Hajizadeh Moghaddam et al, 2008; Muller et al, 1997; Scheel-Kruger and Petersen, 1982). However, the regulatory mechanisms of GABAergic activity in the amygdala in the modulation of anxiety have not been studied extensively. ErbB4 is expressed specifically in interneurons (Lai and Lemke, 1991; Shamir et al, 2012; Woo et al, 2007), and NRG1 promotes the GABA release in cortical and hippocampal slices through ErbB4 (Chen et al, 2010a, b; Wen et al, 2010; Woo et al, 2007). Moreover, NRG1 and ErbB4 are expressed in the amygdala (Lai and Lemke, 1991; Shamir et al, 2012; Woo et al, 2007), suggesting that there is a possible role for the NRG1-ErbB4 pathway in regulating anxiety in this region.

We first used the real-time quantitative fluorescence PCR analysis and the western blotting analysis to test whether the NRG1-ErbB4 expression level was related to the anxiety level. We found that relatively high-anxiety mice showed decreased expression of NRG1 and ErbB4 in BLA. No correlation was observed in the hippocampus and the cortex. Although the mRNA of NRG1 was increased in the hippocampus, the NRG1 protein was not changed in the hippocampus that could be because of the posttranslational modification, the secretion action, and other factors.

To further prove this hypothesis, we infused exogenous NRG1 into the BLA and found that it had no effect on the anxiety-like behaviors of normal mice. However, blocking the NRG1-ErbB4 signaling pathway of the BLA either with ecto-ErbB4, AG1478, or PD, or knocking down the ErbB4 gene increased the anxiety-related behaviors that were shown in the open field test, the EPM test, the social interaction test, and the NSF latency test . The behavioral change was not attributed to the motor activity or the appetite.

Thus, we presumed that amygdala NRG1-ErbB4 signaling could be at a saturated state in normal mice, whereas in high-anxiety mice, NRG1 was downregulated. We indeed found that infusion of exogenous NRG1 into the BLA could produce an anxiolytic effect in relatively high-anxiety mice, strongly supporting the above conclusion. In addition, we found that the anxiolytic effect of exogenous NRG1 was blocked by the ErbB4 inhibitor, again proving that NRG1 could act through ErbB4 receptors in the BLA on the regulation of anxiety-like behaviors. The involvement of NRG1 signaling in anxiety was further supported by our results showing an anxiolytic effect of exogenous NRG1 in the stressed mice.

\section{The Amygdala NRG1-ErbB4 in the Regulation of Neurotransmission}

High GABAergic activity in the amygdala is thought to maintain lower firing rate of pyramidal neurons, and is important for the modulation of anxiety. In the BLA, feedforward GABAergic interneurons synapse heavily onto BLA projection neurons (Li et al, 1996; Szinyei et al, 2000). However, relatively little is known about the regulatory mechanisms that control the inhibitory activity in the amygdala. Our previous studies indicate that NRG1 can increase the evoked GABA release in cortical and hippocampal slices through its receptor ErbB4 (Chen et al, 2010b; Woo et al, 2007). However, the function of NRG1-ErbB4 in the amygdala was not investigated, even though NRG1 and ErbB4 were expressed in the amygdala. Different strengths of NRG1-ErbB4 signaling between the amygdala and the hippocampus may explain different levels of GABAergic activity in these two regions.

We first found that inhibiting the NRG1-ErbB4 signaling pathway in the BLA with NRG1 antagonist (ecto-ErbB4) or ErbB4 antagonist (AG1478) or enhancing it with exogenous NRG1 did not have an effect on the excitatory synaptic transmission in pyramidal neurons in the BLA. To study the effect of NRG1-ErbB4 signaling on local GABAergic transmission in the BLA, monosynaptic eIPSCs were recorded with high $\mathrm{Cl}$-pipette solution. Stimulating electrode was positioned on the thalamic fiber path (to be consistent with eEPSC recording), but inside the BLA, $\sim 100 \mu \mathrm{m}$ from recording electrode. Because of close proximity between stimulating and recording electrode, inhibitory fibers from local GABAergic interneurons rather than long-range GABAergic projections were likely stimulated directly to elicit monosynaptic eIPSCs. In addition, treatment of CNQX and AP5 could also exclude the contamination of disynaptic eIPSCs, indicating they were 
independent of thalamic fiber stimulation. In contrast to excitatory transmission, our further experiments showed that downregulating NRG1-ErbB4 or knocking down the ErbB4 expression within the BLA inhibited the IPSCs, whereas the exogenous NRG1 had no effect on the IPSCs of normal mice. This phenomenon was consistent with the results of the behavioral tests. Thus, we proposed that NRG1-ErbB4 signaling of the BLA mainly acts on GABAergic neurotransmission that is in a saturated state to maintain strong inhibitory control of the BLA neuronal activity in normal mice. To further confirm this conclusion, we measured the IPSCs in brain slices of high-anxiety mice and found that NRG1 could enhance their IPSC through presynaptic mechanisms. Altogether, our results suggest that NRG1-ErbB4 pathway in the BLA might regulate anxiety-like behaviors through GABAergic signaling. In support of this hypothesis, injection of $\mathrm{GABA}_{\mathrm{A}}$ receptor antagonist into the BLA produced the same anxiogenic effect as blocking the NRG1-ErbB4 signaling. In addition, the anxiolytic effect of exogenous NRG1 in high-anxiety mice was blocked by the $\mathrm{GABA}_{\mathrm{A}}$ receptor antagonist.

\section{Etiopathological and Treatment Implications of the NRG1-ErbB4 Pathway}

Compared with the general population, there is an increased prevalence of anxiety disorders among patients who have schizophrenia (Keller, 2006). Relevant epidemiological, genetic/familial, neurobiological, and therapeutic literature complicates the study of anxiety in schizophrenia (Keller, 2006). The relationship between anxiety and schizophrenia has remained controversial (Buckley et al, 2009). Previous studies have showed that NRG1 and its receptor ErbB4 are susceptibility genes for schizophrenia (Mei and Xiong, 2008). Patients who have schizophrenia are more likely to have anxiety disorders compared with the general population (Buckley et al, 2009; Keller, 2006). In this study, we demonstrated that NRG1-ErbB4 signaling is critical for the modulation of anxiety-like behaviors that might help to explain a potential mechanism for the emotional abnormality observed in schizophrenia.

Classical 1,4-benzodiazepines, the standard treatment for anxiety disorders, are not consistently effective, and this is because of their significant side effects, including sedativehypnotic cognitive impairment, muscle relaxant, and memory-impairing effects. Reduced side effects, decreased toxicity, and shortening of the treatment duration are urgent demands for new anxiolytic drugs. Our findings that the administration of exogenous NRG1 into amygdala produces the anxiolytic effect only in high-anxiety mice and also in stressed mice could aid in identifying improved treatments for anxiety disorders. In this respect, it is notable that some individuals who have a generalized anxiety disorder, social anxiety disorder, or panic disorder have abnormal changes in amygdala activities. Medications that modulate the activity of amygdala NRG1-ErbB4 might help in the treatment of such disorders.

\section{FUNDING AND DISCLOSURE}

This work was partly supported by grants from the National Natural Science Foundation of China (81329003, U1201225,
31430032), the Guangzhou Science and Technology Project (7411802013939), the Program for Changjiang Scholars and Innovative Research Team in University (IRT1142), and the NIH. The authors declare no conflict of interest.

\section{REFERENCES}

Abe Y, Namba H, Kato T, Iwakura Y, Nawa H (2011). Neuregulin-1 signals from the periphery regulate AMPA receptor sensitivity and expression in GABAergic interneurons in developing neocortex. J Neurosci 31: 5699-5709.

Adachi M, Autry AE, Covington HE 3rd, Monteggia LM (2009). MeCP2-mediated transcription repression in the basolateral amygdala may underlie heightened anxiety in a mouse model of Rett syndrome. J Neurosci 29: 4218-4227.

Buckley PF, Miller BJ, Lehrer DS, Castle DJ (2009). Psychiatric comorbidities and schizophrenia. Schizophr Bull 35: 383-402.

Chen Y, Hancock ML, Role LW, Talmage DA (2010a). Intramembranous valine linked to schizophrenia is required for neuregulin 1 regulation of the morphological development of cortical neurons. J Neurosci 30: 9199-9208.

Chen YJ, Zhang M, Yin DM, Wen L, Ting A, Wang P et al (2010b). ErbB4 in parvalbumin-positive interneurons is critical for neuregulin 1 regulation of long-term potentiation. Proc Natl Acad Sci USA 107: 21818-21823.

Chieng B, Azriel Y, Mohammadi S, Christie MJ (2011). Distinct cellular properties of identified dopaminergic and GABAergic neurons in the mouse ventral tegmental area. J Physiol 589(Pt 15): $3775-3787$.

Coryell MW, Wunsch AM, Haenfler JM, Allen JE, McBride JL, Davidson BL et al (2008). Restoring acid-sensing ion channel-1a in the amygdala of knock-out mice rescues fear memory but not unconditioned fear responses. J Neurosci 28: 13738-13741.

Davidson BL, Stein CS, Heth JA, Martins I, Kotin RM, Derksen TA et al (2000). Recombinant adeno-associated virus type 2, 4, and 5 vectors: transduction of variant cell types and regions in the mammalian central nervous system. Proc Natl Acad Sci USA 97: 3428-3432.

Etkin A, Prater KE, Schatzberg AF, Menon V, Greicius MD (2009). Disrupted amygdalar subregion functional connectivity and evidence of a compensatory network in generalized anxiety disorder. Arch Gen Psychiatry 66: 1361-1372.

Flores-Gracia C, Nuche-Bricaire A, Crespo-Ramirez M, Miledi R, Fuxe K, Perez de la Mora M (2010). GABA(A) rho receptor mechanisms in the rat amygdala and its role in the modulation of fear and anxiety. Psychopharmacology (Berl) 212: 475-484.

Fox IJ, Kornblum HI (2005). Developmental profile of ErbB receptors in murine central nervous system: implications for functional interactions. J Neurosci Res 79: 584-597.

Garcia RA, Vasudevan K, Buonanno A (2000). The neuregulin receptor ErbB-4 interacts with PDZ-containing proteins at neuronal synapses. Proc Natl Acad Sci USA 97: 3596-3601.

Hajizadeh Moghaddam A, Roohbakhsh A, Rostami P, HeidaryDavishani A, Zarrindast MR (2008). GABA and histamine interaction in the basolateral amygdala of rats in the plus-maze test of anxiety-like behaviors. Pharmacology 82: 59-66.

Holmes WE, Sliwkowski MX, Akita RW, Henzel WJ, Lee J, Park JW et al (1992). Identification of heregulin, a specific activator of p185erbB2. Science 256: 1205-1210.

Huang YZ, Won S, Ali DW, Wang Q, Tanowitz M, Du QS et al (2000). Regulation of neuregulin signaling by PSD-95 interacting with ErbB4 at CNS synapses. Neuron 26: 443-455.

Hugues S, Garcia R (2007). Reorganization of learning-associated prefrontal synaptic plasticity between the recall of recent and remote fear extinction memory. Learn Mem 14: 520-524. 
Johansen JP, Cain CK, Ostroff LE, LeDoux JE (2011). Molecular mechanisms of fear learning and memory. Cell 147: 509-524.

Johnson NJ, Rodgers RJ (1996). Ethological analysis of cholecystokinin (CCKA and CCKB) receptor ligands in the elevated plusmaze test of anxiety in mice. Psychopharmacology (Berl) 124: 355-364.

Keller MB (2006). Prevalence and impact of comorbid anxiety and bipolar disorder. J Clin Psychiatry 67((Suppl 1)): 5-7.

Kessler RC, Berglund P, Demler O, Jin R, Merikangas KR, Walters EE (2005). Lifetime prevalence and age-of-onset distributions of DSM-IV disorders in the National Comorbidity Survey Replication. Arch Gen Psychiatry 62: 593-602.

Koob GF (2009). Brain stress systems in the amygdala and addiction. Brain Res 1293: 61-75.

Krettek JE, Price JL (1978). A description of the amygdaloid complex in the rat and cat with observations on intra-amygdaloid axonal connections. J Comp Neurol 178: 255-280.

Lai C, Lemke G (1991). An extended family of protein-tyrosine kinase genes differentially expressed in the vertebrate nervous system. Neuron 6: 691-704.

Lakso M, Sauer B, Mosinger B Jr, Lee EJ, Manning RW, Yu SH et al (1992). Targeted oncogene activation by site-specific recombination in transgenic mice. Proc Natl Acad Sci USA 89: 6232-6236.

LeDoux JE (2000). Emotion circuits in the brain. Annu Rev Neurosci 23: 155-184.

Lerch-Haner JK, Frierson D, Crawford LK, Beck SG, Deneris ES (2008). Serotonergic transcriptional programming determines maternal behavior and offspring survival. Nat Neurosci 11: 1001-1003.

Li XF, Armony JL, LeDoux JE (1996). GABAA and GABAB receptors differentially regulate synaptic transmission in the auditory thalamo-amygdala pathway: an in vivo microiontophoretic study and a model. Synapse 24: 115-124.

Liu C, Maejima T, Wyler SC, Casadesus G, Herlitze S, Deneris ES (2010). Pet-1 is required across different stages of life to regulate serotonergic function. Nat Neurosci 13: 1190-1198.

Madisen L, Zwingman TA, Sunkin SM, Oh SW, Zariwala HA, Gu H et al (2010). A robust and high-throughput Cre reporting and characterization system for the whole mouse brain. Nat Neurosci 13: 133-140.

Marowsky A, Yanagawa Y, Obata K, Vogt KE (2005). A specialized subclass of interneurons mediates dopaminergic facilitation of amygdala function. Neuron 48: 1025-1037.

McDonald AJ (1998). Cortical pathways to the mammalian amygdala. Prog Neurobiol 55: 257-332.

Mei L, Xiong WC (2008). Neuregulin 1 in neural development, synaptic plasticity and schizophrenia. Nat Rev Neurosci 9: 437-452.

Muller J, Corodimas KP, Fridel Z, LeDoux JE (1997). Functional inactivation of the lateral and basal nuclei of the amygdala by muscimol infusion prevents fear conditioning to an explicit conditioned stimulus and to contextual stimuli. Behav Neurosci 111: 683-691.

Peters J, Dieppa-Perea LM, Melendez LM, Quirk GJ (2010). Induction of fear extinction with hippocampal-infralimbic BDNF. Science 328: 1288-1290.
Ressler KJ, Mayberg HS (2007). Targeting abnormal neural circuits in mood and anxiety disorders: from the laboratory to the clinic. Nat Neurosci 10: 1116-1124.

Rodriguez Manzanares PA, Isoardi NA, Carrer HF, Molina VA (2005). Previous stress facilitates fear memory, attenuates GABAergic inhibition, and increases synaptic plasticity in the rat basolateral amygdala. J Neurosci 25: 8725-8734.

Sanders SK, Shekhar A (1995). Regulation of anxiety by GABAA receptors in the rat amygdala. Pharmacol Biochem Behav 52: 701-706.

Scheel-Kruger J, Petersen EN (1982). Anticonflict effect of the benzodiazepines mediated by a GABAergic mechanism in the amygdala. Eur J Pharmacol 82: 115-116.

Shamir A, Kwon OB, Karavanova I, Vullhorst D, Leiva-Salcedo E, Janssen MJ et al (2012). The importance of the NRG-1/ErbB4 pathway for synaptic plasticity and behaviors associated with psychiatric disorders. J Neurosci 32: 2988-2997.

Silberman Y, Shi L, Brunso-Bechtold JK, Weiner JL (2008). Distinct mechanisms of ethanol potentiation of local and paracapsular GABAergic synapses in the rat basolateral amygdala. J Pharmacol Exp Ther 324: 251-260.

Szinyei C, Heinbockel T, Montagne J, Pape HC (2000). Putative cortical and thalamic inputs elicit convergent excitation in a population of GABAergic interneurons of the lateral amygdala. J Neurosci 20: 8909-8915.

Tamamaki N, Yanagawa Y, Tomioka R, Miyazaki J, Obata K, Kaneko T (2003). Green fluorescent protein expression and colocalization with calretinin, parvalbumin, and somatostatin in the GAD67-GFP knock-in mouse. J Comp Neurol 467: 60-79.

Tidcombe H, Jackson-Fisher A, Mathers K, Stern DF, Gassmann M, Golding JP (2003). Neural and mammary gland defects in ErbB4 knockout mice genetically rescued from embryonic lethality. Proc Natl Acad Sci USA 100: 8281-8286.

Turner BH, Herkenham M (1991). Thalamoamygdaloid projections in the rat: a test of the amygdala's role in sensory processing. J Comp Neurol 313: 295-325.

Tye KM, Prakash R, Kim SY, Fenno LE, Grosenick L, Zarabi H et al (2011). Amygdala circuitry mediating reversible and bidirectional control of anxiety. Nature 471: 358-362.

Wen L, Lu YS, Zhu XH, Li XM, Woo RS, Chen YJ et al (2010). Neuregulin 1 regulates pyramidal neuron activity via ErbB4 in parvalbumin-positive interneurons. Proc Natl Acad Sci USA 107: 1211-1216.

Woo RS, Li XM, Tao Y, Carpenter-Hyland E, Huang YZ, Weber J et al (2007). Neuregulin-1 enhances depolarization-induced GABA release. Neuron 54: 599-610.

Yan HC, Qu HD, Sun LR, Li SJ, Cao X, Fang YY et al (2010). Fuzi polysaccharide-1 produces antidepressant-like effects in mice. Int J Neuropsychopharmacol 13: 623-633.

Zarrindast MR, Solati J, Oryan S, Parivar K (2008). Effect of intraamygdala injection of nicotine and GABA receptor agents on anxiety-like behaviour in rats. Pharmacology 82: 276-284.

Zhu XH, Yan HC, Zhang J, Qu HD, Qiu XS, Chen L et al (2010). Intermittent hypoxia promotes hippocampal neurogenesis and produces antidepressant-like effects in adult rats. J Neurosci 30: 12653-12663.

Supplementary Information accompanies the paper on the Neuropsychopharmacology website (http://www.nature.com/npp) 